\title{
Os Governos FHC e Lula e a política para a força de trabalho civil do Governo Central Brasileiro
}

\author{
The Fernando Henrique Cardoso (FHC) \\ and Luiz Inácio Lula da Silva (Lula) governments and the policy \\ for the civil servant workforce of the Brazilian government
}

Nilson do Rosario Costa ${ }^{1}$ Isabel Lamarca ${ }^{1}$

\footnotetext{
${ }^{1}$ Departamento de Ciências Sociais, Escola Nacional de Saúde Pública, Fundação Oswaldo Cruz. Rua Leopoldo Bulhões 1480/ 923, Manguinhos. 21041210 Rio de Janeiro RJ. nilson@ensp.fiocruz.br
}

\begin{abstract}
This article analyzes the configuration of the active civil servant workforce of the Brazilian government during Fernando Henrique Cardoso - FHC - (1995-2002) and Luiz Inácio Lula da Silva - Lula - (2003-2010) mandates. The article associates the condition of the workforce of the Brazilian government with the changes in the government coalition. The residual participation of the Ministry of Health (MOH) in the direct provision of public services influenced the downward trend of the federal workforce. The implementation of the Unified Health System (SUS) was strongly affected by the structural adjustment of the workforce at the federal level during the decades of 1990 and 2000.
\end{abstract}

Key words State reform, Macroeconomic adjustment, Civil servants, State bureaucracy, Lula, Unified Heath System
Resumo O artigo analisa a configuração da força de trabalho civil ativa do governo central brasileiro nos mandatos de Fernando Henrique Cardoso (1995-2002) e de Luiz Inácio Lula da Silva (2003-2010). O artigo associa a condição da força de trabalho do governo central brasileiro às mudanças na coalizão governamental. A residual participação do Ministério da Saúde (MS) na prestação direta de serviços públicos influenciou na trajetória declinante da força de trabalho federal. A implantação do SUS foi fortemente afetada pelo ajuste estrutural da força de trabalho no nível federal ao longo das décadas de 1990 e 2000.

Palavras-chave Reforma do Estado, Ajuste macroeconômico, Emprego público, Burocracia pública, Lula, Sistema Único de Saúde 


\section{Introdução}

Este artigo analisa a configuração da força de trabalho civil ativa do governo central brasileiro nos governos Fernando Henrique Cardoso (1995-2002) e Luiz Inácio Lula da Silva (20032010). A evolução da força de trabalho civil é considerada como uma variável de diferenciação da natureza da política governamental. Os governos orientados ao mercado adotam a agenda do Estado menos ativo ou mínimo, com a redução da propriedade estatal e do quantitativo de funcionários públicos. Na tradição brasileira, os governos autoritários ou de esquerda caminharam no sentido contrário ao fortalecerem, historicamente, o papel econômico das organizações estatais $^{1}$. Metodologicamente, os governos de FHC e Lula, no âmbito da Nova Democracia brasileira, foram resultado de orientações políticas marcadamente opostas em relação a várias áreas de políticas públicas ${ }^{2}$. O governo Lula definia-se pela tradição nacional-desenvolvimentista, enquanto que a coalizão de FHC era explicitamente favorável à reforma do Estado e a internacionalização da economia brasileira. A orientação do governo FHC foi também influenciada pelos compromissos exigidos pelo ajuste estrutural da década de 1990 e pelo questionamento do papel do Estado como provedor direto de serviços sociais e de infraestrutura. O governo Lula propunha uma retomada do desenvolvimentismo com o retorno do protagonismo das empresas e organizações estatais na produção econômica e prestação social. Pretende-se analisar o quanto a política para a força de trabalho civil do governo central brasileiro foi constrangida ou favorecida por essas orientações governamentais discrepantes.

É importante assinalar que a Constituição Federal (CF) de 1988 define, como princípio básico, o Brasil como uma República Federativa. A organização político administrativa compreende a União, os Estados, os Municípios e o Distrito Federal, todos autônomos em termos constitucionais. A Constituição de 1988 define também os poderes da União, do Legislativo, do Executivo e do Judiciário ${ }^{3}$. Este trabalho focaliza exclusivamente a evolução da força de trabalho civil da instância federativa União ou governo central e dos seus poderes.

Nas décadas de 1980 e 1990, a capacidade de investir e saldar os compromissos da dívida externa dependia das agências de cooperação multilaterais, como Banco Mundial e Fundo Monetário Internacional, e do mercado financeiro in- ternacional. Não resta dúvida hoje que o poder de coordenação política do governo central brasileiro esteve duramente afetado em decorrência da crise fiscal e da vulnerabilidade cambial. Os atores transnacionais exigiam condutas cooperativas com o capital externo e a integração incondicional da economia nacional à globalização. A inserção vulnerável do país no sistema internacional cobrava a privatização de ativos públicos e a desregulamentação dos mercados de produtos, financeiros e de trabalho, alterando profundamente as funções do Estado nacional ${ }^{4}$. A agenda específica da reforma do Estado assumiu centralidade dos formuladores de políticas públicas nesse contexto adverso. De fato, o estreitamento do espaço para as políticas nacionais favoreceu a proposta de mudança nas funções do Estado nacional pela privatização de empresas públicas de infraestrutura, a diminuição do funcionalismo público, reforma previdenciária e a seletividade de programas sociais ${ }^{5,6}$.

Ainda assim, Haggard e Kaufman ${ }^{7}$ sugeriram controlar quatro variáveis críticas para compreender a extensão das mudanças nas funções do Estado nas economias vulneráveis, como a brasileira, na década de 1990: (1) a condição de desequilíbrio macroeconômico, que imporia diferentes graus de urgência em responder às iniciativas de estabilização; (2) o apoio político das coalizões nacionais às orientações para o ajuste estrutural; (3) a capacidade institucional dos Estados nacionais e (4) o tipo de regime político, se democrático ou autoritário, que patrocinava o ajuste.

\section{$\mathrm{O}$ ajuste macroeconômico \\ e o bônus do crescimento}

A análise da experiência brasileira da década de 1990 desde a perspectiva dos autores é particularmente instigante porque a coalizão política do governo FHC assumiu a urgência da agenda da estabilização em razão da crise da hiperinflação, da desorganização das finanças públicas e da vulnerabilidade cambial ${ }^{8}$. O governo FHC foi, assim, favorável à estabilização macroeconômica com integração à globalização e à cooperação com investimento externo. Nesse contexto, a agenda de reforma do aparelho de Estado brasileiro esteve diretamente associada à orientação geral do ajuste macroeconômico. Ainda assim, o governo FHC teve que considerar o legado de um aparelho de Estado fortemente intervencionista, fortalecido pela democratização e pela Constituição de 1988. Além disso, a nova democracia instaurou um sistema multifacetado de representação de 
interesses, tornando anacrônico o processo decisório exclusivamente concentrado no Executivo federal como fora durante o regime autoritário ${ }^{4}$. Draibe $^{9}$ assinala, também nesse sentido, que a falência da centralização decisória do regime autoritário trouxe automaticamente para a arena política a voz de lideranças do Legislativo, Judiciário, instâncias federativas então secundárias - Estados e Municípios - e coalizões de especialistas setoriais 9 . O novo sistema político partidário corroboraria a segmentação na intermediação de interesses na arena política ${ }^{10}$.

A agenda da reforma do Estado teve que negociar, portanto, no contexto específico da nova democracia e a capacidade de veto de atores ligados aos interesses domésticos. Já foi demonstrado que a principal razão de veto à reforma do Estado é que ela impunha custos específicos a setores sociais concretos, como os servidores públicos, e benefícios difusos em nome da sociedade ${ }^{11}$.

A proposta formal para reestruturação da força de trabalho do poder Executivo do primeiro mandato de FHC (1995-1998) foi o Plano Diretor da Reforma Aparelho de Estado de 1995 (PDRAE). Ele definia como principal objetivo estratégico de reforma a separação de funções do Executivo como proprietário de empresas e de prestador de serviços. Nessa opção, o Executivo deveria privatizar as empresas de sua propriedade ou conceder a atividade a terceiros. As funções econômicas do Estado brasileiro estariam limitadas à regulação por meio de agências autônomas. O PDRAE acolhia, assim, a ideia um novo papel para a função econômica do poder Executivo e dos próprios Ministérios, alterando em profundidade o modelo de governança verticalizado praticado no país. Pela verticalização o Executivo federal brasileiro deteve o controle direto de muitas empresas de infraestrutura, definindo política de preços, investimento, rentabilidade e contratação de força de trabalho. As empresas estatais ofereciam ao Executivo grande espaço para a condução das decisões econômicas, especialmente no segmento dos serviços de utilidade pública ${ }^{12-14}$. A agenda do PDRAE criticava o modelo de comando e controle do nacional desenvolvimentismo, que favoreceria o excesso de pessoal nas empresas públicas, monopólio público, metas organizacionais ambíguas e inconsistentes e déficit no controle das empresas estatais pelo Congresso, tribunais ou mesmo pelo ministério gestor.

No campo da provisão direta de serviços tipicamente sociais, o primeiro governo FHC propunha uma reforma abrangente do contingente de pessoal vinculado ao poder Executivo federal. A orientação era a de que os serviços providos aos cidadãos, como saúde, educação, cultura e pesquisa científica, de interesse público, mas não de exclusiva prestação pelo Estado, deveriam ser delegados às organizações públicas não estatais, cujo modelo legal se consubstanciou nas denominadas organizações sociais (OSS), criadas pela Lei $9.637^{15}$.

O PDRAE produziu a modelagem das OSS e a Emenda Constitucional 19 (EC-19) em 1998, modificando o artigo 39 da Constituição Federal de 1988. Este artigo dispunha sobre o regime o jurídico único e os planos de carreira para os servidores da administração pública direta, das autarquias e das fundações públicas. A EC-19 possibilitou o retorno do regime celetista para as autarquias e fundações, resgatando o modelo existente na Constituição Federal de 1967.

Em paralelo ao PDRAE, durante os dois mandatos, FHC ampliou o "programa de privatização das empresas públicas”, iniciado pelo governo Collor de Mello em 1991. Anuatti-Neto et al. ${ }^{16}$ chamam atenção que o programa brasileiro de privatização abrangeu três partes: (a) o Programa Nacional de Desestatização (PND), federal, iniciado em 1991; (b) programas similares no âmbito estadual, que começaram em 1996 e (c) o programa de privatização do setor de telecomunicação. A composição total do programa por setores mostra que a privatização do setor elétrico foi responsável por $31 \%$ do valor total dos leilões; telecomunicações, $31 \%$; aço, $8 \%$; mineração, $8 \%$, óleo e gás, 7\%; petroquímica, 7\%, financeiro, $6 \%$, e outros, $2 \%$. A privatização atingiu seu pico em 1997-98, período responsável por $69 \%$ do valor total da receita e transferência de dívida do setor público.

Diretamente associadas ao processo de privatização, as agências reguladoras independentes foram criadas pelo Executivo federal: a Agência Nacional do Petróleo (ANP) ${ }^{17,18}$; a Agência Nacional de Energia Elétrica (Aneel) ${ }^{19,20}$; a Agência Nacional de Telecomunicações (Anatel) ${ }^{21,22} \mathrm{e}$ a Agência Nacional de Transportes Terrestres $(\mathrm{ANTT})^{23,24}$.

No campo da disciplina fiscal, duas iniciativas do governo FHC se destacaram: a aprovação de novas regras referentes ao endividamento público e a promulgação da Lei de Responsabilidade Fiscal (LRF) ${ }^{25}$, que estabeleceram normas e parâmetros de finanças públicas voltadas para a responsabilidade na gestão fiscal, e limites de gastos com pessoal diante das receitas líquidas de cada ente federativo (União, Estados e Municípios). 
Ao contrário da ampla gama de iniciativas de reforma do governo FHC, o governo Lula foi paradoxalmente tímido na implantação de uma agenda própria desenvolvimentista. A assunção dessa agenda implicaria em uma forte retomada do ativismo governamental por meio da reestatização das empresas de infraestrutura e abrandamento ou abandono das metas da política macroeconômica.

Assim, Lula não promoveu rupturas importantes na condução macroeconômica deixada pelo ajuste estrutural do governo anterior. Mesmo antes de ganhar as eleições, a sua coalizão de apoio sinalizou para o mercado financeiro e investidores internacionais que não alteraria nos fundamentos da gestão econômica de FHC. O superávit primário, o regime de meta da inflação e o câmbio flutuante foram mantidos ${ }^{26}$. A LRF continuou em vigor, intocada. As privatizações não foram revertidas. Pode-se aqui recorrer à noção de "path dependency" (dependência de trajetória) proposta pela abordagem neoinstitucionalista histórica, que assinala o impacto dos legados políticos sobre as escolhas dos atores sociais. Isto significa que uma política pública, ao iniciar uma trajetória tem os custos de reversão aumentados, pois as barreirase arranjos instituídos obstruirão uma mudança fácil da escolha original. A noção de path dependency explicaria a permanência de determinados aspectos da política macroeconômica da década de 1990 do país e a resiliência às inovações formuladas por orientação política divergente. A continuidade da disciplina fiscal no governo Lula comprovaria que a nova coalização, independente da orientação política, ficou relativamente constrangida pelas decisões macroeconômicas dos anos $1990^{26}$.

O constrangimento ao governo Lula na condução macroeconômica operou a despeito das grandes mudanças na economia mundial no começo da década de 2000. As condições de crescimento e integração da economia mundial mudaram significativamente em relação à década de 1990. O Brasil foi uma das economias ganhadoras na mudança do padrão de crescimento econômico, como raros precedentes históricos, alavancado pela China ${ }^{27}$. Rodrik ${ }^{28}$ comenta, não sem certa perplexidade, que "o mais intrigante é que os países que exibiram o melhor desempenho, nos últimos anos, são os que menos se basearam em financiamento externo. A China, superestrela mundial de crescimento, tem um enorme superávit em conta corrente, o que significa estar operando como um emprestador líquido para o restante do mundo. A América Latina, inclusive Ar- gentina e Brasil, vem registrando, recentemente, confortáveis superávits externos. O vigor e a resistência a choques nos mercados de capital devem-se, em não pequena medida, ao fato de terem se tornado emprestadores líquidos para o restante do mundo, após anos funcionando como tomadores líquidos de empréstimos" ${ }^{28}$.

A explosão do comércio mundial de bens primários (commodities), sustentada pela forte demanda do crescimento chinês e de outros países emergentes, fortaleceu as economias periféricas, reduzindo drasticamente o constrangimento externo e a interferência das agências internacionais $^{28}$. A Tabela 1 mostra evolução das reservas internacionais e a redução da dívida pública externa de curto prazo brasileira, ampliando o espaço de decisão para a implantação de políticas orientadas aos interesses domésticos.

A Tabela 1 permite concluir que, a despeito da manutenção do tripé do ajuste macroeconômico, o governo Lula obteve um substancial bônus para recuperar a matriz nacional-desenvolvimentista para a força de trabalho civil do governo central. Esse bônus foi reforçado pelo crescimento contínuo da economia brasileira entre os anos 20032008. Nesse contexto benigno, qual correção específica realizou Lula na política do governo anterior para a força de trabalho civil do governo federal? Ou teria a coalizão capitaneada pelo Partido dos Trabalhadores mantido também intoca-

Tabela 1. Brasil - reservas internacionais: liquidez (1995-2010).

\begin{tabular}{cccc}
\hline Ano & $\begin{array}{c}\text { Em US\$ } \\
\text { milhões (A) }\end{array}$ & $\begin{array}{c}\text { Dívida Externa de } \\
\text { Curto Prazo (B) }\end{array}$ & $\begin{array}{c}\text { B/A } \\
\mathbf{1 0 0}\end{array}$ \\
\hline 1995 & 51840 & 29943 & 57,8 \\
1996 & 60110 & 37787 & 62,9 \\
1997 & 52173 & 36715 & 70,4 \\
1998 & 44556 & 26298 & 59,0 \\
1999 & 36342 & 26609 & 73,2 \\
2000 & 33011 & 27420 & 83,1 \\
2001 & 35866 & 27658 & 77,1 \\
2002 & 37823 & 23395 & 61,9 \\
2003 & 49296 & 20194 & 41,0 \\
2004 & 52935 & 18744 & 35,4 \\
2005 & 53799 & 18776 & 34,9 \\
2006 & 85839 & 20323 & 23,7 \\
2007 & 180334 & 38901 & 21,6 \\
2008 & 206806 & 36444 & 17,6 \\
2009 & 239054 & 30972 & 13,0 \\
2010 & 288575 & 57307 & 19,9 \\
\hline
\end{tabular}

Fonte: Conjuntura Econômica ${ }^{29}$. 
da a política da força de trabalho civil como fizera em relação à gestão macroeconômica?

\section{A força de trabalho civil do governo central}

A coalizão que conduziu Lula à presidência vetava ruidosamente a agenda da reforma do Estado implantada pelo governo FHC. Orientado pela perspectiva liberalizante, o governo FHC realizou, especialmente no primeiro mandato, uma redução sem precedentes nas despesas com pessoal do governo central brasileiro. Em 1995, como mostra a Tabela 2, a despesa corrente com pessoal alcançou a $29 \%$ da receita corrente do governo central. Ao fim do segundo mandato de FHC a despesa corrente com pessoal foi drasticamente reduzida a $19 \%$ da receita corrente do governo central.

Apesar de fortalecido pela conjuntura internacional, o governo Lula não reverteu substancialmente o padrão da despesa pública com pessoal legado por FHC. A Tabela 3 mostra, entretanto, que a evolução das despesas com pessoal nos dois governos FHC sempre ficou abaixo da receita corrente da União. O governo Lula foi claramente mais generoso em relação ao comprometimento das receitas da União com as despesas com pessoal do que FHC durante os dois mandatos.

Essa generosidade favoreceu, no biênio 20092010, últimos dois anos de mandato de Lula, a significativa ampliação nas despesas com pessoal em relação à receita da União, ainda que não tenha alcançado os quase $30 \%$ contabilizados em 1995. Chama atenção, adicionalmente, na Tabela 4 , que a variação na despesa corrente com pessoal no último mandato de Lula foi ligeiramente maior do que a receita corrente do governo federal, invertendo por completo o padrão observado por FHC.

O efeito do ajuste nas despesas com pessoal, realizado pelo governo $\mathrm{FHC}$, teve um impacto específico no quantitativo da força de trabalho ativa do poder Executivo federal, mas não atingiu os poderes Legislativo e Judiciário em razão da autonomia orçamentária que a CF de 1998 outorgou-lhes. As perdas promovidas pelo governo FHC foram concentradas nas atividades do Executivo que fora alvo direto do PDRAE, da descentralização e do programa de privatização. A Tabela 4 mostra na primeira coluna que o governo central brasileiro contava, em 1995, início do primeiro mandato FHC, com 712.726 servidores públicos civis ativos nos três poderes. Em 2002, a quantidade de servidores civis ativos apresentava o resultado da drástica redução de mais de 75 mil empregos públicos, caindo para 632.879.

A força de trabalho civil voltou a crescer ao longo do primeiro governo Lula, alcançando 691.604 em 2006. No fim do segundo mandato, em 2010, atingiu 769.570 servidores civis ativos, contingente superior ao existente em 1995. A evo-

Tabela 2. Brasil - participação da despesa líquida com pessoal na receita corrente (RC) do governo central brasileiro: 1995-2010 (R\$ milhões correntes).

\begin{tabular}{cccc}
\hline Ano & $\begin{array}{c}\text { Despesa líquida de } \\
\text { pessoal da União (A) }\end{array}$ & $\begin{array}{c}\text { Receita Corrente do Governo } \\
\text { Central (União) }(\mathbf{B})\end{array}$ & $\begin{array}{c}\text { \% das despesas com pessoal na } \\
\text { receita corrente da União (A/B 100) }\end{array}$ \\
\hline 1995 & 37825,5 & 127.093 .6 & 29,8 \\
1996 & 40900,9 & $152.271,1$ & 26,8 \\
1997 & 44529,7 & $175.271,1$ & 25,4 \\
1998 & 47944,5 & $200.358,9$ & 23,9 \\
1999 & 51571,0 & $218.022,1$ & 23,7 \\
2000 & 56093,3 & $252.517,5$ & 22,2 \\
2001 & 59212,2 & $289.410,9$ & 20,5 \\
2002 & 64415,9 & $343.075,0$ & 18,8 \\
2003 & 70213,9 & $384.447,0$ & 18,3 \\
2004 & 79959,9 & $450.590,0$ & 17,7 \\
2005 & 82761,7 & $527.324,6$ & 15,7 \\
2006 & 102496,7 & $584.067,5$ & 17,5 \\
2007 & 112596,0 & $658.884,4$ & 17,1 \\
2008 & 130636,9 & $754.735,5$ & 17,3 \\
2009 & 149648,8 & $775.406,6$ & 19,3 \\
2010 & 166590,5 & $890.137,0$ & 18,7 \\
\hline
\end{tabular}

Fonte: Brasil $^{30}$. 


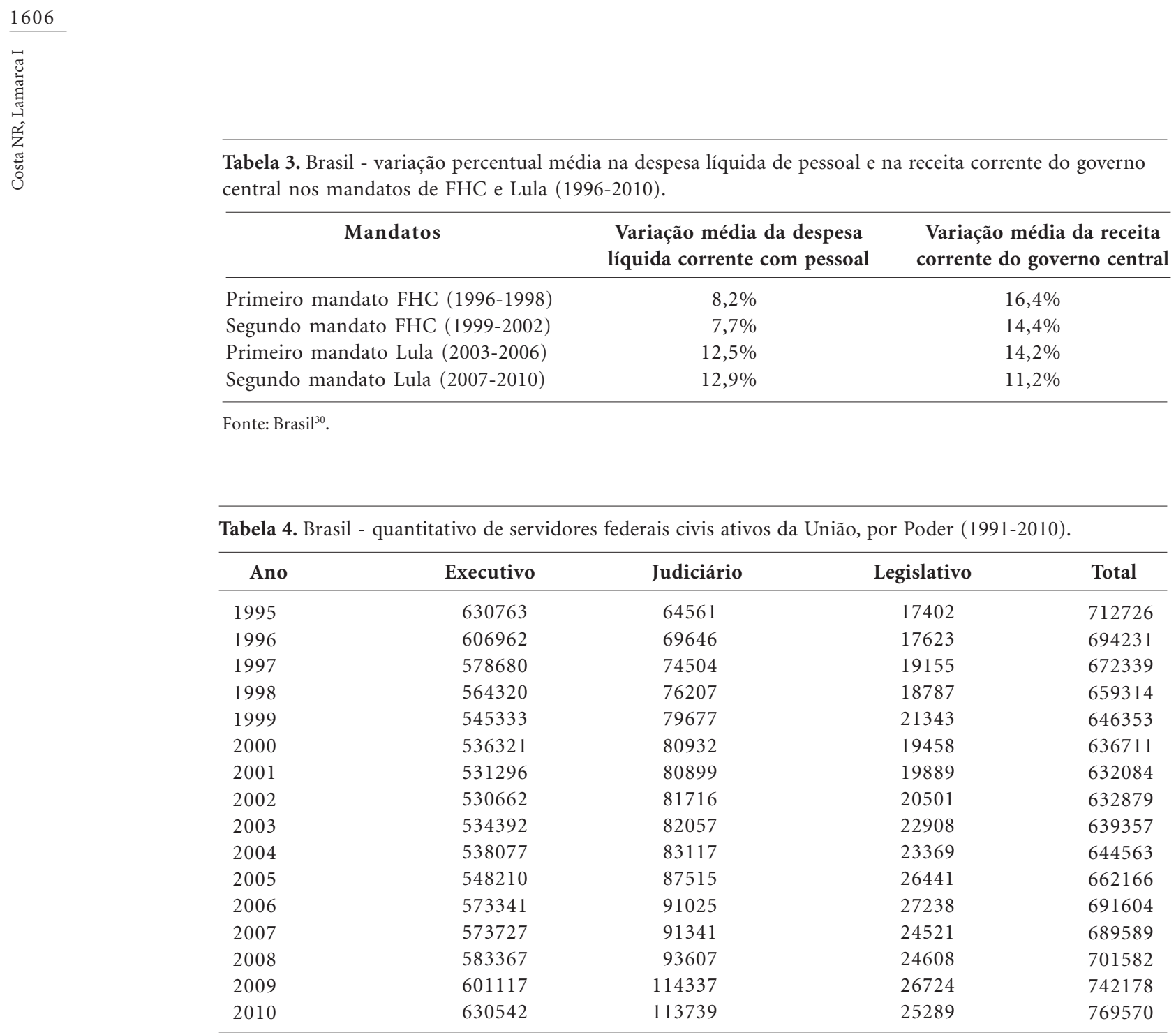

Fonte: Brasili $1^{30,31}$.

lução da taxa de servidores públicos federais civis ativos por 10 mil habitantes, na Tabela 5, comprova a bem sucedida orientação do governo Lula pela expansão da força de trabalho do governo federal.

As Tabelas 4 e 5 mostram que a redução da força de trabalho civil ativa não foi maior no governo FHC graças ao crescimento do contingente de servidores ativos do Legislativo e do Judiciário federal. Durante os dois mandatos de Lula, o Judiciário manteve o ritmo expansivo de crescimento de servidores ativos. A força de trabalho ativa do legislativo ficou estabilizada nos períodos de governo de FHC, voltando a crescer durante os governos Lula.

É importante assinalar que a Lei de Responsabilidade Fiscal, ao permitir que os contratos de terceirização de mão-de-obra fossem contabilizados como Outras Despesas de Pessoal, gerou um grande incentivo à terceirização da prestação de serviços e dos vínculos de trabalho pelos governos e gestores ${ }^{32}$. Esse incentivo explica a diversificação das formas de contrato de trabalho no setor público, durante os mandatos de FHC, tendência que não se reverteu no governo Lula, apesar do aumento de ingressos com a realização de concursos públicos comentado anteriormente. A grande quantidade de contratos por tempo determinado na administração civil federal indica que os dois regimes presidenciais não abdicaram de uma composição híbrida da força de trabalho federal para acomodar a demanda por cargos das coalizões políticas.

Outra dimensão do hibridismo da força de trabalho civil do governo central é a nomeação para os "cargos de confiança." A Tabela 6 mostra claramente a existência de um padrão institucional na distribuição dos cargos de confiança bastante parcimonioso. Essas nomeações nunca ultrapassaram, nos dois governos, mais de $4 \%$ do 
número de servidores concursados ativos do Poder Executivo.

Loureiro et al..$^{33}$ argumentam que a disposição dos cargos de alto escalão da burocracia é resultado direto da relação entre o sistema político e a administração pública. A principal variável institucional nessa relação é o tipo de presidencialismo que, no Brasil, permite ao presidente a livre nomeação da alta burocracia para o poder Executivo. Em busca de apoio do legislativo, as nomeações são utilizadas para acomodar as indicações dos partidos aliados ao governo. Segundo os autores, este loteamento dos cargos nos Ministérios só é possível porque a alta administração pública brasileira está estruturada a partir dos cargos de livre provimento do Executivo e não das carreiras públicas.

Tabela 5. Brasil - taxa de servidores federais civis ativos da União, por Poder, por 10 mil habitantes em: 1995, 1998, 2002, 2006 e 2008.

\begin{tabular}{cccc}
\hline Ano & Executivo & Judiciário & Legislativo \\
\hline 1995 & 40,5 & 4,1 & 1,1 \\
1998 & 34,9 & 4,7 & 1,2 \\
2002 & 30,4 & 4,7 & 1,2 \\
2006 & 30,7 & 4,9 & 1,5 \\
2010 & 33,1 & 6,0 & 1,3 \\
\hline
\end{tabular}

Fonte: Brasil ${ }^{30,31}$.

\section{Conclusão}

Este trabalho demonstra a mudança ocorrida na política para a força de trabalho do governo federal entre os governos FHC e Lula. A agenda da Reforma do Estado do governo FHC foi levada a cabo no que tange à redução da força de trabalho ativa do Executivo federal. A clivagem de orientação dos dois governos foi influenciada pelas mudanças de contexto macroeconômicos e pela orientação da coalizão política governamental. O trabalho assinala que três grandes iniciativas de reforma do Estado afetaram a força de trabalho do governo central durante o governo FHC: a reforma administrativa, a privatização e a descentralização.

A reforma administrativa afetou o papel do governo central na provisão direta de serviços de saúde, educação de nível superior e cultura e o fomento à pesquisa e desenvolvimento científico. Houve veto ao projeto de delegação massiva do desenvolvimento dessas atividades a terceiros, pela conversão de unidades públicas federais ao modelo das Organizações Sociais, proposto pelo PDRAE. Ainda assim, a paralisação na década de 1990 nos concursos públicos federais para as unidades federais produziu estagnação e envelhecimento da força de trabalho do governo central nas áreas sociais, instituições de ensino federal e pesquisa científica.

A privatização, embora tenha pouco progredido após 1998, afetou significativamente a quan-

Tabela 6. Brasil - percentual de ocupantes de DAS nos níveis de função 1-6 em relação ao total de servidores públicos ativos do governo central - 1997-2010.

\begin{tabular}{lccc}
\hline Ano & $\begin{array}{c}\text { Força de Trabalho } \\
\text { Ativa do Executivo }\end{array}$ & $\begin{array}{c}\text { Ocupantes de DAS } \\
\text { de todos os níveis }\end{array}$ & $\%$ \\
\hline 1997 & 578680 & 17607 & 3,04 \\
1998 & 564320 & 17183 & 3,04 \\
1999 & 545333 & 16306 & 2,99 \\
2000 & 536321 & 17389 & 3,24 \\
2001 & 531296 & 17995 & 3,39 \\
2002 & 530662 & 18374 & 3,46 \\
2003 & 534392 & 17559 & 3,29 \\
2004 & 538077 & 19083 & 3,55 \\
2005 & 548210 & 19925 & 3,63 \\
2006 & 573341 & 17797 & 3,10 \\
2007 & 573727 & 20187 & 3,52 \\
2008 & 583367 & 20597 & 3,53 \\
2009 & 601117 & 21217 & 3,53 \\
2010 & 630542 & 21870 & 3,47 \\
$\%$ Médio 1997-2010 & - & - & 3,34 \\
\hline
\end{tabular}

Fonte: Brasil $^{30}$. 
tidade de trabalhadores das empresas públicas e empresas de economia mista do Executivo federal. O processo de separação de funções foi setorialmente difundido no governo FHC pela privatização de ativos públicos na infraestrutura, criação das agências reguladoras com autoridade independente e autonomia para operar fora da linha de controle hierárquico do Executivo. Esse modo de regulação representaria, segundo os seus defensores, uma nova fronteira para a administração pública nas economias industrializadas $^{34}$. Entretanto, na área social do governo federal a separação de funções foi obstaculizada.

Já a descentralização teve um expressivo efeito na atuação do governo federal na área social. Os Municípios assumiram a provisão de bens públicos sem restrição ${ }^{35}$. A saúde foi o setor onde mais fortemente a devolução da provisão direta da assistência à saúde aos Municípios promoveu a redução da força de trabalho do Executivo $\mathrm{Fe}$ deral. O processo de descentralização das responsabilidades de gestão e da prestação de serviços do setor saúde foi acompanhado da transferência de um quadro significativo de servidores do Ministério da Saúde (MS) para as unidades de saúde e secretarias estaduais e municipais. Cabe ressaltar que o ônus da cessão é da administração federal, sendo que esses servidores constituem uma das contrapartidas asseguradas pelo governo federal, diante do aumento de responsabilidade dos estados e municípios na prestação dos serviços de saúde ${ }^{36}$.

O efeito combinado dos processos econômicos e institucionais se materializou no reduzido número de cargos preenchidos por concurso público no Executivo federal, consolidando a política restritiva adotada para a força de trabalho durante o governo FHC. A mudança na lógica de incorporação de pessoal e no sistema de carreiras, no período de 1995-2002, configurou um padrão institucional restritivo de recrutamento e sustentação da força de trabalho no Executivo federal.

A conjuntura macroeconômica favorável possibilitou ao governo Lula ampliação da força de trabalho civil do governo federal e a retomada do papel empregador de servidores públicos estatutários. Essa ampliação da força de trabalho respondeu aos compromissos desenvolvimentistas de campanha do candidato Lula e acolheu também a pressão do Tribunal de Contas da União (TCU) e do Ministério Público do Trabalho (MPT) para a substituição por estatutários dos funcionários terceirizados ou temporários. No período 2003-2006 ingressaram 57.906 servi- dores por meio de concurso público e 51.964 ingressaram por contratos de tempo determinado. Entre 2007 e 2010, já no segundo mandato do Governo Lula foram admitidos 97.627 servidores públicos e 60.056 contratados por tempo determinado ${ }^{37}$. Cabe avaliar o quanto este novo esforço de incorporação de novos servidores públicos foi efetivo em termos alocativos, favorecendo as atividades que mais perderam no esforço de redução das funções do governo central do PDRAE do primeiro governo FHC.

O comportamento evolutivo da força de trabalho do Judiciário e do Legislativo federais na década de 1990 demonstra o papel especifico da regra institucional da independência dos poderes sobre o comportamento da burocracia pública no Brasil. A independência destes poderes constitucionais permitiu consolidar força de trabalho, minimizando o impacto da proposta de reforma do aparelho de Estado.

Em relação às nomeações por critério partidário, o preenchimento destes cargos pelas coalizões de FH e de Lula foi alvo de regulamentações visando fortalecer as carreiras de Estado. No governo FHC, o foco foi na descentralização, delegando aos Ministros o poder de nomeação até os cargos de confiança de nível 4 . O governo Lula se preocupou em ampliar o percentual de participação de servidores de carreira nestes cargos, restringindo a participação de não servidores federais concursados ao patamar de $25 \%$, para os cargos de confiança 1, 2 e 3 e $50 \%$ para os para os cargos de confiança 4.

A pesquisa sobre o perfil da alta e média burocracia do Executivo da União, desenvolvida por D’Araújo ${ }^{38}$, auxilia na compreensão da utilização parcimoniosa das nomeações pelo Executivo. A pesquisadora argumenta que, embora se espere que o espaço dos ministérios seja usado para as trocas políticas, os diversos setores do governo seriam tratados com cuidados técnicos bem mais apurados, favorecendo a 'blindagem técnica' e preservando o insulamento burocrático.

A literatura contemporânea tem chamado atenção para dois pontos em relação à blindagem técnica: o déficit democrático associado ao insulamento burocrático e a insuficiência de mensuração do desempenho do aparelho de Estado. Em relação ao primeiro ponto, chama atenção que a atuação completamente insulada da burocracia não é virtuosa em si porque reduziria "os limites da arena política, o que significa a exclusão de partidos políticos, do Congresso e das demandas populares" ${ }^{39}$. O segundo ponto vincula-se à dificuldade de medir o desempenho do setor públi- 
co. A introdução de formas de contratualização foi obstaculizada durante os dois governos Lula por ser considerada como um subproduto da agenda neoliberal e da privatização do Estado. Essa obstrução paralisou a introdução de ações de modernização do Estado brasileiro sob o ponto de vista de transparência, responsabilidade e respeito aos direitos ${ }^{40}$. Nesse contexto, o expressivo reflorescimento da burocracia dos poderes da União nos últimos anos tem consolidado uma inquietante situação de baixa responsabilização da burocracia federal que em nada favorece o controle democrático das atividades governamentais.

Alberto et al. ${ }^{41}$ assinalam também que o incremento de servidores do Executivo federal foi expressivo durante o governo Lula, porém reconhecem que a área da saúde teve um crescimento do número de servidores ativos abaixo do aumento médio do conjunto das áreas e bem inferior ao da área da educação, por exemplo. No âmbito do MS, apesar das necessidades de fortalecimento da coordenação nacional do SUS, não se observaria de forma tão nítida a adoção de uma política ativa e integrada do Governo Federal de incorporação de quadros qualificados para o conjunto do setor. Isso explicaria, segundo as autoras, a tímida expansão do número de servidores federais da saúde no período, reiterando a fragilidade histórica das carreiras federais nessa área. Embora a prestação federal direta de serviços tenha se retraído no período da implantação do SUS, como já assinalado, as autoras chamam também a atenção para a precariedade da situação de vínculos dos trabalhadores federais mesmo em áreas técnicas estratégicas para a condução e coordenação nacional da política de saú$\mathrm{de}^{41}$. Esse diagnóstico fragiliza a tese de que teria ocorrido uma especial implantação do regime de "planejamento integrado" no governo Lula, que o diferenciaria substancialmente, em relação às funções MS, do governo FHC ${ }^{42}$. A inconsequente volatilidade programática do MS, a exemplo do plano "Mais Saúde - Direito de Todos", lança- do no segundo governo Lula (2007-2010) e descartado sem maiores explicações na atual gestão federal (governo Dilma, da mesma coalizão política) - comprovaria o abandono das funções de coordenação do MS brasileiro. A saída do MS da prestação direta de serviços e a estagnação do financiamento federal para o SUS são parte do processo de privatização e fragmentação do Sistema de Saúde Brasileiro. Em várias áreas críticas do setor saúde do país a ausência na coordenação do MS tem sido uma ameaça direta aos direito à saúde da população. Esse é um diagnóstico aplicável à atuação dos governos federais nos últimos 25 anos.

Quando se busca demarcar as diferenças entre os governos Lula e FHC, a maioria das análises não esclarece que os dois mandatos do Lula priorizaram um padrão de intervenção social. A função do governo federal no setor saúde foi obviamente afetada por essa escolha, assim como as funções de coordenação do MS. A literatura da economia do bem estar social tem o cuidado de separar as instituições de política social em duas grandes modalidades: transferência de renda e prestação de serviços. Aplicando a tipologia ao Brasil, na primeira modalidade ficam as instituições que concentram as despesas governamentais destinadas à previdência social, Bolsa Família, LOAS, seguro-desemprego e abono salarial. Na segunda, as instituições das áreas associadas à prestação direta de serviços em hospitais, ambulatórios, postos de saúde, escolas, universidades, etc. Os dois mandatos de Lula consolidaram e ampliaram um padrão de intervenção social na modalidade "transferência de renda" em detrimento do financiamento relativo às áreas de prestação de serviços públicos, como saúde ${ }^{43}$. Portanto, a prestação de serviços sociais públicos não está na agenda de prioridades do governo federal nos anos recentes. O volume de recursos federais destinados ao SUS tem sido proporcionalmente declinante nos últimos anos no âmbito do pacto da federação ${ }^{44}$.

\section{Colaboradores}

NR Costa e I Lamarca participaram igualmente de todas as etapas de elaboração do artigo. 
Referências

1. Bielschowsky R. Pensamento Econômico Brasileiro. O Ciclo Ideológico do Desenvolvimentismo. Rio de Janeiro: Contraponto; 1988.

2. Nakahodo SN, Savoia JR. A reforma da previdência no Brasil: estudo comparativo dos governos Fernando Henrique Cardoso e Lula. Rev. bras. Ci. Soc. 2008; 23(66):45-58.

3. Brasil. Constituição da República Federativa do Brasil de 1988. Diário Oficial da União 1988; 5 out.

4. Diniz E. Crise, Governabilidade e Reforma do Estado: em busca de um novo paradigma. In: Gerschman S, Vianna MLTW, editoras. A Miragem da Modernidade. Democracia e Políticas Sociais no Contexto da Globalização. Rio de Janeiro: Editora Fiocruz; 1997.

5. Ugá MA. Ajuste Estrutural, Governabilidade e Democracia. In: Gerschman S, Vianna MLTW, editoras. A Miragem da Modernidade. Democracia e Políticas Sociais no Contexto da Globalização. Rio de Janeiro: Editora Fiocruz; 1997.

6. Marques RM, Batich M, Mendes A. Previdência Social Brasileira: um balanço da reforma. São Paulo em Perspectiva 2003; 17(1):111-121.

7. Haggard S, Kaufman RR. The Politics of Economic Adjustment. New Jersey: Princeton University Press; 1992.

8. Castro LB. Privatização, Abertura e Desindexação: A Primeira Metade dos Anos 90. In: Giambiagi F Villela A, Castro LB, Hermann J, organizadores. Economia Brasileira Contemporânea (1945-2004). Rio de Janeiro: Elsevier; 2005.

9. Draibe SM. Há Tendências e Tendências: com que Estado de Bem Estar Social Haveremos de Conviver? Campinas: Unicamp, NEPP; 1999. (Cadernos de Pesquisa, n. 10)

10. Vianna MLTW. A Americanização Perversa da Seguridade Social no Brasil. Rio de Janeiro: REVAN, IUPERJ, UCAM; 1998.

11. Pierson P. Politics in Time: History, Institutions and Social Analysis. New Jersey: Princeton University Press; 2004.

12. Martins L. 1985. Estado Capitalista e Burocracia no Brasil Pós 64. Rio de Janeiro: Paz e Terra; 1985.

13. Schneider B. 1994. Burocracia Pública e Política Industrial no Brasil. Rio de Janeiro: Editora Sumaré; 1994.

14. Geddes B. 1994. The Politician's Dilemma: building State Capacity in Latin American. Berkeley: University of California Press; 1994.

15. Brasil. Lei 9.637, de 15 de maio de 1998. Dispõe sobre a qualificação de entidades como organizações sociais, a criação do Programa Nacional de Publicização, a extinção dos órgãos e entidades que menciona e a absorção de suas atividades por organizações sociais, e dá outras providências. Diá rio Oficial da União 1998; 18 maio.

16. Anuatti-Neto F, Barossi-Filho M, Carvalho AG, Macedo R. Os efeitos da privatização sobre o desempenho econômico e financeiro das empresas privatizadas. Rev. Bras. Econ. 2005; 59(2):151-175.
17. Brasil. Lei No 9.478, de 6 de agosto de 1997. Dispõe sobre a política energética nacional, as atividades relativas ao monopólio do petróleo, institui o Conselho Nacional de Política Energética e a Agência Nacional do Petróleo e dá outras providências. Diário Oficial da União 1997; 7 ago.

18. Brasil. Decreto No 2.455, de 14 de janeiro de 1998 Implanta a Agência Nacional do Petróleo - ANP, autarquia sob regime especial, aprova sua Estrutura Regimental e o Quadro Demonstrativo dos Cargos em Comissão e Funções de Confiança e dá outras providências. Diário Oficial da União 1998; 15 jan.

19. Brasil. Lei No 9.427, de 26 de dezembro de 1996. Institui a Agência Nacional de Energia Elétrica ANEEL, disciplina o regime das concessões de serviços públicos de energia elétrica e dá outras providências. Diário Oficial da União 1996; 27 dez.

20. Brasil. Decreto No 2.335, de 6 de outubro de 1997. Constitui a Agência Nacional de Energia Elétrica ANEEL, autarquia sob regime especial, aprova sua Estrutura Regimental e o Quadro Demonstrativo dos Cargos em Comissão e Funções de Confiança e dá outras providências. Diário Oficial da União 1997; 7 out.

21. Brasil. Lei No 9.472, de 16 de julho de 1997. Dispõe sobre a organização dos serviços de telecomunicacões, a criação e funcionamento de um órgão regulador e outros aspectos institucionais, nos termos da Emenda Constitucional no 8, de 1995. Diário Oficial da União 1997; 17 jul.

22. Brasil. Decreto No 2.338, de 7 de outubro de 1997. Aprova o Regulamento da Agência Nacional de Telecomunicações e dá outras providências. Diário Oficial da União 1997; 7 out.

23. Brasil. Lei No 10.233 , de 5 de junho de 2001. Dispõe sobre a reestruturação dos transportes aquaviário e terrestre, cria o Conselho Nacional de Integração de Políticas de Transporte, a Agência Nacional de Transportes Terrestres, a Agência Nacional de Transportes Aquaviários e o Departamento Nacional de Infra-Estrutura de Transportes, e dá outras providências. Diário Oficial da União 2001; 6 jun.

24. Brasil. Decreto No 4.130, de 13 de fevereiro de 2002 . Aprova o Regulamento e o Quadro Demonstrativo dos Cargos Comissionados e dos Cargos Comissionados Técnicos da Agência Nacional de Transportes Terrestres - ANTT, e dá outras providências. Diário Oficial da União 2002; $13 \mathrm{fev}$

25. Brasil. Lei Complementar $n^{\circ} 101$, de 4 de maio de 2000. Estabelece normas de finanças públicas voltadas para a responsabilidade na gestão fiscal e dá outras providências. Diário Oficial da União 2000; 5 maio.

26. Carneiro R. A Supremacia dos Mercados e a Política Econômica do Governo Lula nov. 2005/abr. 2006;7. (Política Econômica em Foco, no 7 )

27. Arora V, Vamvakidis A. China's Economic Grow: International Spillovers. China \&World Economy 2011; 19(5):31-46

28. Rodrik D. A Morte da Globalização. Jornal Valor Econômico 2008; 14 jul. 12 jan. p. A13.

29. Iaquinto K. Precisamos ajudar a resolver. Conjuntura Econômica 2012; 66(3):17. 
30. Brasil. Ministério do Planejamento (MP). Boletim Estatístico de Pessoal. Julho de 2011. Brasília: MP; 2011.

31. Brasil. Ministério da Saúde (MS). DATASUS. [página na Internet]. [acessado 2012 ago 1]. Disponível em: www.datasus.gov.br

32. Costa NR, Ribeiro JM, Silva PLB. Reforma do Estado e Mudança Organizacional. Cien Saude Colet 2000; 5(2):427-442,

33. Loureiro MR, Abrucio FL, Rosa CA. Radiografia da alta burocracia federal brasileira: o caso do Ministério da Fazenda. Rev. Serviço Público 1998; 49(4):46-81.

34. Lane JE. The Public Sector: Concepts, Models and Approaches. London: Sage; 1993.

35. Arretche MTS. Políticas sociais no Brasil: descentralização em um Estado federativo. Rev. Bras. Ciências Soc. 1999; 14(40):111-141.

36. Universidade de Brasília (UnB). Centro de Estudos Avançados Multidisciplinares. Subsídios para o Plano de Reordenamento dos Recursos Humanos no âmbito do Ministério da Saúde: tendências e situação dos recursos humanos do poder executivo federal, 19902004 [relatório]. [acessado 2012 jul 14]. Disponível em: http://www.observarh.org.br/nesp/sistema/ banco/20060519022306_rel_sittend.pdf

37. Brasil. Ministério do Planejamento, Orçamento e Gestão. Secretaria de Recursos Humanos do Ministério do Planejamento, Orçamento e Gestão, Brasília. Boletim Estatístico de Pessoal 128 e 183. [acessado 2012 ago 1]. Disponível em: www.mpog.gov.br

38. D’Araujo MC. A elite dirigente do governo Lula. Rio de Janeiro: CPDOC, FGV; 2009.

39. Loureiro MR, Olivieri C, Martes AC. 2011. Burocratas, Partidos e Grupos de Interesse: o debate sobre política e burocracia no Brasil. In: Loureiro MR, Abrucio FL, Pacheco RS, editores. Burocracia e Política no Brasil - Desafios para a ordem democrática no século XXI. São Paulo: FGV; 2011. p. 73-108.

40. Pacheco RS. A Agenda da Nova Gestão Pública. In: Loureiro MR, Abrucio FL, Pacheco RS, editores. Burocracia e Política no Brasil - Desafios para a ordem democrática no século XXI. São Paulo: FGV; 2011. p. 277-306.

41. Alberto LG, Machado CV, Teixeira M. O quadro de trabalhadores federais em saúde no Brasil: uma análise no contexto dos anos 2000. Physis 2011; 21(4):1537-1560

42. Machado CV, Baptista TWF, Lima LD. O planejamento nacional da política de saúde no Brasil: estratégias e instrumentos nos anos 2000. Cien Saude Colet 2010; 15(5):2367-2382.

43. Costa NR. 2012. Qualidade dos serviços públicos: qual a agenda? Jornal Valor Econômico 2012; 24 abr. p. A12.

44. Dain S. 2007. Os vários mundos do financiamento da Saúde no Brasil: uma tentativa de integração. Cien Saude Colet 2007; 12(Supl.):1851-1864.

Artigo apresentado em 04/10/2012

Aprovado em 19/01/2012

Versão final apresentada em 15/02/2012 
